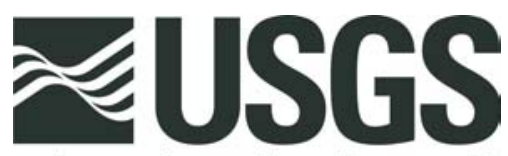

science for a changing world

\title{
Digital recovery, modification, and analysis of Tetra Tech seismic horizon mapping, National Petroleum Reserve Alaska (NPRA), northern Alaska
}

by R.W. Saltus, C.S. Kulander, and C.J. Potter

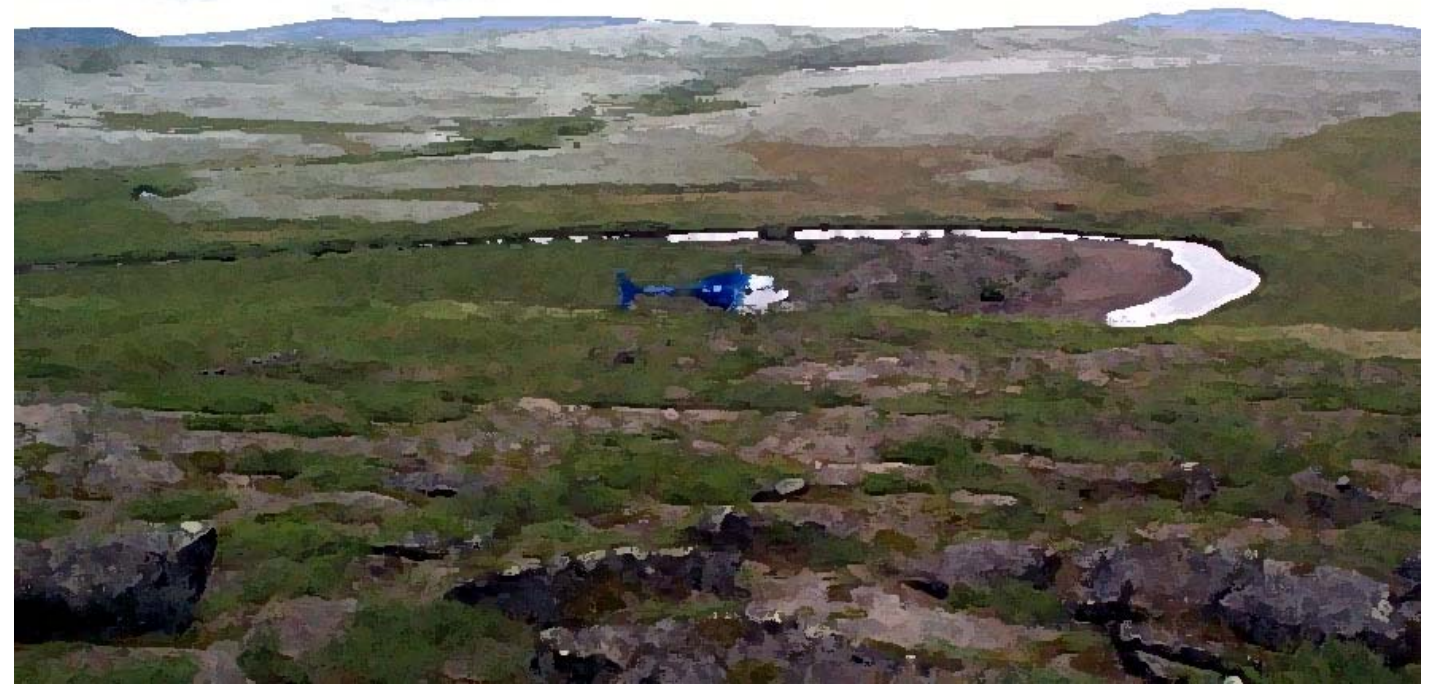

\section{Open-File Report 02-0111 2002}

This report is preliminary and has not been reviewed for conformity with U.S. Geological Survey editorial standards or with the North American Stratigraphic Code. Any use of trade, firm, or product names is for descriptive purposes only and does not imply endorsement by the U.S. Government.

U.S. DEPARTMENT OF THE INTERIOR

U.S. GEOLOGICAL SURVEY

Denver, Colorado

This report is available at http://pubs.usgs.gov/of/2002/ofr-02-111/ 


\section{Abstract}

We have digitized, modified, and analyzed seismic interpretation maps of 12 subsurface stratigraphic horizons spanning portions of the National Petroleum Reserve in Alaska (NPRA). These original maps were prepared by Tetra Tech, Inc., based on about 15,000 miles of seismic data collected from 1974 to 1981 . We have also digitized interpreted faults and seismic velocities from Tetra Tech maps. The seismic surfaces were digitized as two-way travel time horizons and converted to depth using Tetra Tech seismic velocities. The depth surfaces were then modified by long-wavelength corrections based on recent USGS seismic re-interpretation along regional seismic lines. We have developed and executed an algorithm to identify and calculate statistics on the area, volume, height, and depth of closed structures based on these seismic horizons. These closure statistics are tabulated and have been used as input to oil and gas assessment calculations for the region. Directories accompanying this report contain basic digitized data, processed data, maps, tabulations of closure statistics, and software relating to this project.

\section{Introduction}

The potential for significant subsurface oil and gas accumulation has long been suspected in northwestern Alaska. Early twentieth century exploration and reports by the USGS, along with a perceived possibility of strategic oil shortfall, led President Warren G. Harding to create the Naval Petroleum Reserve No. 4 in 1923. This region, spanning most of northwestern Alaska (Figure 1) was renamed the National Petroleum Reserve in Alaska (NPRA) in 1976.

Geophysical exploration of the NPRA region began by the U.S. Navy in 1944. During the years 1945 to 1952 several small oil and gas accumulations were discovered, including the Barrow gas fields and the Umiat oil field. About 3,500 miles of seismic reflection and some refraction data were collected during this period.

The discovery of oil at Prudhoe Bay in 1968, coupled with the 1973 oil crisis, led to renewed exploration of NPRA beginning in 1974. Between then and 1981, the U.S. Navy, the U.S. Geological Survey, Husky Oil NPR Operations, Tetra Tech, Inc., and Geophysical Services, Inc., undertook a major exploration effort, along with several other subcontractors. This work led to collection and publication of extensive geological and geophysical information and analysis including seismic reflection data (e.g., Gryc, 1988).

Although seismic processing techniques and concepts of seismic stratigraphic interpretation have undergone significant improvement in the last 20 years, the detailed original interpretation of these data remains valuable. These interpretations were done at a map scale and extent that has not been reproduced in the published literature since then. The Tetra Tech interpretations are based on analysis of all the seismic data; much of the subsequent work by the USGS has been concentrated on a reprocessed and merged regional subset of the original seismic grid (Figure 1). 
The Tetra Tech contour maps summarize the interpretation of about 15,000 miles of seismic data collected from 1974 to 1981 (Tetra Tech, 1982). The seismic grid covers the bulk of the NPRA region with a spacing of about 6 miles east to west and 8 miles north to south (Figure 1). In this report we describe digitization, modification, and analysis that we have done on these data in support of the USGS 2002 oil and gas assessment of NPRA.

\section{Digitization of Tetra Tech seismic horizon and velocity maps}

Selected Tetra Tech maps were digitized by Center Line Data under contract to the USGS. The contractor used a hand-aided automated approach based on scanning of the original maps and conversion of the relevant line information to digital coordinates. The digitized data (Figure 2; Table 1) include seismic time horizon contour lines, fault traces, and contours of seismic velocity estimates. In addition, one seismic depth map (basement) was digitized by hand by the USGS for comparison with calculated basement depths.

Most of the digitized maps are from the Tetra Tech final report (Tetra Tech, 1982) and were scanned at the original scale of 1:500,000. In addition, two seismic horizons were digitized at 1:250,000 scale from the Tetra Tech 1980 summary report (Tetra Tech, 1980). Visual checks were made to assure that the digitized contours faithfully represent most of the detail of the maps at their original scale. The number of digitized points and the original digitized point file names are listed in Table 1. Table 1 also lists the data file names for each of these datasets. These data files are contained in the data folder that is part of this report.

We digitized two-way travel time, rather than depth, maps because these maps are more directly related to the original seismic data. The time maps are also more detailed, in general, than the comparable depth horizon maps. In addition, digitization of the time horizon provides for more direct comparison of the Tetra Tech interpretation with the seismic data themselves and with recent USGS seismic interpretation (Kulander and others, Chap. SI).

\section{Time to depth conversion}

Conversion of the Tetra Tech two-way travel time horizon maps to depth horizons was done as follows (see Tables 1, 2, and Figure 2 for stratigraphic names and abbreviations):

1. Nanushuk (NNU) horizon. The Tetra Tech 0400, 0450, 0500, and 0550 horizons were merged by shifting the datums to match the 0500 surface. We merged these horizons in order to produce a single surface amenable to closure analysis as discussed below. This merged time horizon map was converted to depth by multiplication with seismic velocities digitized from Tetra Tech Map 53 (see Table 1). Depths were then subtracted from surface elevations (based on a $300 \mathrm{~m}$ digital elevation model; Riehle and others, 1996) to produce an elevation map.

2. Fortress Mtn (FM) horizon. The Tetra Tech FM time horizon map was converted to depth by multiplication with velocities digitized from Tetra Tech Map 54 (see 
Table 1). Depths were then subtracted from surface elevations (based on a $300 \mathrm{~m}$ digital elevation model; Riehle and others, 1996) to produce an elevation map.

3. Lower Cretaceous Unconformity (LCU) horizon. The Tetra Tech 0700 and 0720 horizons were merged by shifting the datum of the 0720 surface to match the 0700 surface at their common boundary. This merged time horizon map was then converted to depth by multiplication with seismic velocities digitized from Tetra Tech Map 54 (see Table 1). Depths were then subtracted from surface elevations (based on a $300 \mathrm{~m}$ digital elevation model; Riehle and others, 1996) to produce an elevation map.

4. Sag River (SAG) horizon. The Tetra Tech 1000 and 1020 horizons were merged by shifting the datum of the 1020 surface to match the 1000 surface at their common boundary. The elevation of the Sag River horizon was then calculated by multiplying the difference between the LCU and Sag River time maps by the Tetra Tech velocities digitized from Map 56 and subtracting that from the LCU elevation map.

5. Sadlerochit (SAD) and Echooka (ECH) horizons. These horizon maps were constructed from their respective Tetra Tech time maps (1040 and 1100) by multiplying velocities from Tetra Tech Map 57 times the differences of these horizons with the Tetra Tech 1000 time horizon. These depths were then subtracted from the Sag River elevation to produce the elevation maps.

6. Lisburne (LIS) horizon. This depth map was constructed from the Echooka depth horizon map by adjusting that horizon based on USGS mapping of the Lisburne time horizon (see next section).

7. Intermediate Composite Features (ICF) and Alapah (ALA) horizons. These horizon maps were constructed from their respective Tetra Tech time maps (ICF and 1300) by multiplying velocities from Tetra Tech Map 58 times the differences of these horizons with the Tetra Tech 1100 horizon. These interval depths were then subtracted from the Echooka elevation to produce the elevation maps.

8. Endicott (END) and Basement (BMT) horizons. These horizon maps were constructed from their respective Tetra Tech time maps (1400 and 1500) by multiplying velocities from Tetra Tech Map 58 times the differences of these horizons with the Tetra Tech 1100 horizon. These interval depths were then subtracted from the Echooka elevation to produce the elevation maps. 


\section{Adjustment of seismic horizons based on USGS seismic processing and horizon mapping}

Recent USGS reprocessing and analysis along a set of regional seismic lines and some detailed lines (Figure 1; Ikelman, 1986; Miller and others, 2000; Miller and other 2001) has yielded new picks of the major seismic horizons of NPRA (Kulander and others, Chap. SI). In order to combine this updated analysis on the regional lines with the more detailed Tetra Tech mapping, we have adjusted the Tetra Tech mapping to fit the long wavelengths of the revised USGS surfaces. This correction was applied as follows:

1. The digitized Tetra Tech time contours were interpolated to a regular $1 \mathrm{~km}$ grid using the minimum curvature algorithm (Briggs, 1974).

2. Tetra Tech time values were interpolated from these grids along the USGS regional seismic lines and the USGS time picks were then subtracted to yield time differences.

3. The time differences were smoothed along each line using a third order polynomial and converted to depths using the appropriate digitized Tetra Tech interval velocity for the horizon (Table 2 summarizes these smoothed differences).

4. A long-wavelength surface grid was interpolated from the smoothed depth differences.

5. This long-wavelength grid was then added to the relevant Tetra Tech depth grids to produce the revised depth horizons.

The difference map statistics and file names resulting from the correction process are summarized in Table 2.

\section{Closed structure identification and analysis}

Structural closures on seismic horizons may contain hydrocarbon accumulations if oil generation and trapping mechanisms are favorable. For the purpose of hydrocarbon assessment it is useful to collect statistics on the shapes, sizes, and depths of these potential containers. We located, counted, and measured structural closures on the NPRA seismic depth horizons using the multi-step approach outlined below. The custom software we developed to implement this algorithm is contained in the software directory that accompanies this report. The results of these analyses are summarized in Tables 3 and 4.

1. Contour lines were generated and digitally captured for each seismic horizon. The resolution of the results depends on the contour line interval and grid cell size (contours were generated using the Oasis montaj geophysical processing package, Geosoft, Inc.).

2. Closed contours were selected out of the complete contour line set (using FORTRAN code findclosures.f - see software directory).

3. Fundamental contours were selected out of the closed contour line set. A fundamental contour is one that is not contained within another closed contour (FORTRAN code sortclosures3.f - see software directory). 
4. Area, volume, average height, and depth-to-top statistics were gathered for each fundamental closed contour (FORTRAN code closurestats.f - see software directory).

5. Maps and spreadsheets summarize the closure statistics (these statistics are tabulated in Tables 3 and 4; closure maps in the Appendix; data spreadsheets in the Appendix).

\section{Discussion}

\section{Resolution of digitization and gridding}

The digitized time horizon data differ slightly from the original Tetra Tech maps. The 1 $\mathrm{km}$ data grids constructed from the digitized contours are smoothed across the mapped faults because the minimum curvature algorithm does not allow discontinuities within a grid. Instead, a smooth surface is fitted to the digitized data points. In addition, contour lines produced from the gridded data will not exactly reproduce the original contours even in the absence of faults. For example, the exact shapes of culminating contour lines (innermost closed highs and lows) are, in general, slightly modified by the minimum curvature algorithm. Also, tight contour saddles in the original Tetra Tech maps tend to be broadened slightly in the grid. It appears that the Tetra Tech maps were contoured by hand - thus, we expect the machine contours to differ in some details. In addition, local high and low culminations in the original data are not recorded on the Tetra Tech maps so they cannot be replicated in our digitization. None of these subtle differences lead to any problems for our interpretation of these data. However, future users of these data should consider regridding from the original digitized contours if the application warrants it.

\section{Conversion to depth}

Digitized seismic time horizons must be converted to depth to be relevant to analysis of potential hydrocarbon trapping structures. The seismic horizons were digitized from time surface maps to preserve the greatest detail in the interpretations. Times were converted to depth using the smooth maps of seismic velocity prepared by Tetra Tech (see Table 1 for list of all maps digitized). No attempt has been made to analyze differences between the Tetra Tech velocities and those used by the USGS in subsequent seismic processing. Instead, comparisons between Tetra Tech and recent USGS mapping were made in twoway travel time. Corrections were then applied to the depth-converted Tetra Tech surfaces by multiplying the time differences by the relevant Tetra Tech velocity for that interval, smoothing the result, gridding, and then applying the smoothed correction.

As a check of the absolute depth accuracy for our seismic interfaces, we have compared the seismic depths with borehole-determined depths for several of the horizons. The calculated seismic depths differ from borehole depths by hundreds to thousands of feet at individual boreholes (Table 2 and maps cited therein). The greatest discrepancies occur in northern-most NPRA, along the Barrow Arch. The seismically estimated depths are too great in this region which indicates that the Tetra Tech estimated velocities are systematically high, primarily for the interval from the surface to the LCU. 
In general, however, the surfaces defined by these differences are smooth and are not expected to modify the closure geometries in a significant way. Long-wavelength correction surfaces, fit through the differences at the borehole locations, show median slopes of seven to thirty $\mathrm{ft} / \mathrm{mile}$. The average slopes of seismic closures are generally five to twenty times this value. For this reason, and because the boreholes are located primarily in the northern part of NPRA where the plays are generally stratigraphic rather than structural, we have chosen not to adjust the seismic surfaces to the known borehole depths. However, future users of these data should consider making these adjustments, depending on project needs. The best way to improve the depth accuracy of the seismic horizons would be to systematically improve the shallow velocity model by the combined analysis of seismic, lithologic, and potential field (gravity and magnetic) data.

\section{Closure statistics}

The resolution of the closed structure analysis depends on the detail present in the depth horizon surfaces that form the input to the closure identification and measurement procedure. For this study, a grid interval of $1 \mathrm{~km}$ was used. This means that the smallest possible closure area is $1 \mathrm{~km}^{2}$ (250 acres) and all closure shapes are blocky at this resolution.

Closures that intersect the boundaries of the mapped horizons could be missed by the procedure because they will not create closed contours. To address this issue, the data grids were extrapolated beyond the data boundaries to allow structures at the data boundaries the possibility of being closed beyond the data perimeter by the minimum curvature algorithm. The portion of areas or volumes of closures beyond the data or play boundaries were not counted in the sizes tabulated. On the closure maps (Table 3, Appendix), these regions show up as white space within a closure boundary.

The choice of contour interval affects the results. The larger the contour interval, the more likely it is that closures with maximum heights smaller than that contour interval may be missed by the procedure. We used the smallest contour interval practical for the given interface, typically 20 feet. Given the resolution of the seismic interpretations, we did not reduce the contour resolution below $20 \mathrm{ft}$.

The bulk of the closure identification and measurement procedure was implemented in three custom computer codes (see software directory that accompanies this report), findclosures, sortclosures3, and closurestats. These programs are written in Fortran 77 and were compiled and run on a Sun Solaris computer using the standard Sun F77 compiler.

The findclosures program scans through the contour lines and extracts only those contours that close (i.e., the first and last point of the contour line is identical).

The sortclosures 3 program tests each closed contour to determine whether it is contained inside another closed contour. If it is, the program compares the contour value of the tested contour line with that of the encompassing contour to determine whether the enclosing contour is a high or low closure. Closed contours contained within other 
closed contours are eliminated from the test set. The sortclosures 3 program outputs all the closed contours that are not contained within other closed contours.

These closed contours and the accompanying grid of horizon elevations serve as input to the closurestats program. For each closed contour the number of positive elevation grid cells (i.e., those grid cells with elevation values greater than the contour value) is tabulated to determine the positive area of the closure. These positive differences are also summed to calculate total volume of the closure. Average height of the closure is determined by dividing the volume by the area. In some cases closures with some positive volume also encompass small closed lows. The area of these lows is not counted as part of the positive closure area. Also, the volume of these lows does not subtract from the positive closure volume. Statistics are tabulated for each closure and are output in an ASCII format that will input readily into a spreadsheet program such as Microsoft Excel.

Closure statistics are listed in Table 3. The details for each are contained in the spreadsheets in the directory accompanying this report. The number of closures tabulated range from 7 in the Ellesmerian Echooka North play to 213 for the Nanushuk horizon in the Brookian Topset Structural play. Most of the horizons have median areas greater than 1 thousand acres and $95^{\text {th }}$ percentile areas greater than 20 thousand acres. The Echooka horizon closures have the greatest median and $95^{\text {th }}$ percentile areas. Several horizons have median average closure heights greater than 100 feet and $95^{\text {th }}$ percentile heights greater than 600 feet.

In all cases area and height of closures are positively correlated. In other words, larger closures have greater vertical relief. Table 4 summarizes the statistics for these correlations. In addition, detailed tables and charts for each horizon are available in the Stats directory accompanying this report. Spearman correlation coefficients for the closure data distributions range from 0.56 to 0.92 , with typical values of about 0.7 . The Spearman correlation measure ranges from 0 (non-correlated) to 1 (complete correlation). Because the area and height values are not normally distributed, the Spearman rank correlation value is probably the most significant indicator of degree of correlation (i.e., Book, 1977). The slope of the correlations (ratio of height in feet to area in kiloacres) ranges from about 0.2 (for the Echooka horizon in the Ellesmerian Echooka North play) to 50 (for the ICF horizon in the Thrust Belt play), with most of the values between 5 and 25.

\section{Use of closure statistics in assessment methodology}

The purpose of identifying and tabulating statistics for closures on the seismic horizon surfaces is to provide data for evaluation of potential oil and gas accumulations. These statistics are primarily applicable to structural, and not stratigraphic, hydrocarbon plays. The closure statistics must be evaluated on a play by play basis to determine whether the values are appropriate as determined or whether they should be modified based on other geological and/or structural information. For example, closures smaller than a given size may be regarded as beyond the real resolution of the seismic method, or certain specific large closures may either be eliminated or subdivided based on ideas about the 
stratigraphy of the rocks involved, erosional breaching of potential reservoirs, or postulated structural compartmentalization.

As currently implemented, the various closures statistics (number of closures, area, heights, and depth to top) are entered into the assessment as ranges of values. The statistical form of the distribution is given along with a lower truncation point, a median value, and a 95\% value (Schuenemeyer, Chap. ME). Monte Carlo simulation runs that examine discrete populations created from these distributions then determine the final assessment numbers. This approach does not capture all the data we have about the exact form of these distributions from actual seismic measurement of these structures. For example, we know with great confidence the exact number and sizes of the larger closures - the Monte Carlo simulations should be constrained to this known scenario. In practice, this will only affect plays for which the structural parameters describing the gross dome geometries are the limiting factor for hydrocarbon accumulation. In general, other factors such as vertical and lateral extent of reservoir facies, porosity, seal integrity, and charge are more likely to provide limiting factors in calculation of final probabilities.

\section{Conclusions}

Detailed interpretations of extensive seismic reflection data collected in the highly prospective NPRA region of northern Alaska have been digitized, processed and analyzed to assist in hydrocarbon assessment. These data form important components of a three-dimensional characterization of the Mississippian to Cenozoic stratigraphy of this portion of the North Slope basin. Recent USGS interpretations differ in detail from the earlier interpretations by Tetra Tech that form the basis for the digitized maps. We have modified the earlier interpretations based on this recent revised mapping, but maintain the short-wavelength details of the earlier work. Analysis of the seismic horizons yields statistics on the area, volume, height, and depths of seismic closures that may relate to potential hydrocarbon trapping structures. These closure statistics will be used to constrain assessment of oil and gas resources in the region. 


\section{References}

Bird, K. J., 1988, Alaskan North Slope stratigraphic nomenclature and data summary for government-drilled wells, in Gryc, G., ed., Geology and exploration of the National Petroleum Reserve in Alaska, 1974 to 1982: U. S. Geological Survey Professional Paper 1399 , p. 317-354.

Bird, K. J., Connor, C. L., Tailleur, I. L., Silberman, M. L., and Christie, J. L., 1978, Granite on the Barrow arch, northeast NPRA, in Johnson, K. M., ed., The United States Geological Survey in Alaska: Accomplishments during 1977: U. S. Geological Survey Circular 772-B, p. B24-B25.

Book, S.A., 1977, Statistics Basic Techniques for Solving Applied Problems: McGrawHill (New York), 511 pp.

Briggs, I.C., 1974, Machine contouring using minimum curvature: Geophysics, v. 39, n. 1, p. 39-48.

Gryc, George, 1985, The National Petroleum Reserve in Alaska - Earth-Science Considerations: U.S. Geological Survey Professional Paper 1240-C, 94 pp.

Gryc, George (ed.), 1988, Geology and Exploration of the National Petroleum Reserve in Alaska, 1974 to 1982: U.S. Geological Survey Professional Paper 1399, 940 pp.

Ikelman, J.A. (editor), 1986, Catalog of Geological and Geophysical Data for the National Petroleum Reserve in Alaska - Key to Geophysical Records Documentation No. 16 (Revised Edition), National Geophysical Data Center, Boulder, Colorado, p. 24-25.

Kulander, C.S., Grow, J., Potter, C., Saltus, R., and Killgore, M., 2002, Interpreted regional seismic reflection lines, National Petoleum Reserve - Alaska: This report, ?? pp.

Miller, J.J., Agena, W.F., Lee, W.L., Zihlman, F.N., Grow, J.A., Taylor, D.J., Killgore, M., Oliver, H.L., 2000, Regional seismic lines reprocessed using post-stack processing techniques: National Petroleum Reserve - Alaska (NPRA), United States Geological Survey Open File Report 00-286.

Miller, J.J, Agena, W. F., Lee, M.W., Zihlman, F.N., Grow, J.A., Taylor, D.J., Killgore, Michele, and Oliver, H.L, 2001, Four Regional Seismic Lines: National Petroleum Reserve -- Alaska (Supplement to U.S. Geological Survey Open-File Report 00-286), U.S. Geological Survey Open-File Report 01-0337.

Riehle, J.R., Fleming, M.D., Molnia, B.F., Dover, J.H., Kelley, J.S., Miller, M.L., Nokleberg, W.J., Plafker, G., and Till, A.B., 1996, Digital shaded-relief image of Alaska: U.S. Geological Survey Map I-2585, scale 1:2,500,000, with accompanying pamphlet, 11 pp. 
Schuenemeyer, this report, Assessment methodology, ?? pp.

Tetra Tech, 1981, Summary Report FY '80, Tetra Tech Report No. 8003 (including maps at 1:500,000 and 1:250,000 scale).

Tetra Tech, 1982, Petroleum exploration of NPRA 1974-1981 (Final Report):

Tetra Tech Report No. 8200 (including maps at 1:500,000 scale). 


\section{APPENDICIES}

Five directories accompany this report and contain data, maps, and software related to this project. Each directory is described here. The filenames are indexed in the tables in this report. Also, each directory contains a file named "AAAREADME.TXT" that gives basic information on the files in that directory.

\section{Data}

This directory contains ASCII data files for the basic digitized data and for the final seismic horizon grids. The *.XYZ files are ASCII files with header information that gives the data column definitions. Latitude and Longitudes (LAT and LON) data are on the NAD27 Datum. X and Y coordinates are in meters, on the NAD27 datum, and projected using an Albers equal area projection with standard parallels of 55 and 65 degrees north, a base latitude of 50 degrees north, and a central meridian of 154 degrees west. The HRZ*.XYZ files contain three data columns: X, Y, Z, where X and $\mathrm{Y}$ are locations in meters and $\mathrm{Z}$ is elevation in kilofeet.

\section{Map}

This directory contains PDF formatted maps of the seismic horizons, time differences, and closure analyses. See Tables 1, 2, and 3 for association of filenames to seismic horizons.

\section{Software}

This directory contains the FORTRAN 77 source code for the three custom software codes developed for identification and measurement of closed structures on the seismic horizons.

\section{Spreadsheets}

This directory contains Microsoft Excel spreadsheets containing tables of closure statistics and summary statistics from the closure analyses. See Table 3 for more information.

\section{Stats}

This directory contains ASCII formatted printouts that detail the statistics of closure area verses height for the different horizons that were studied. 


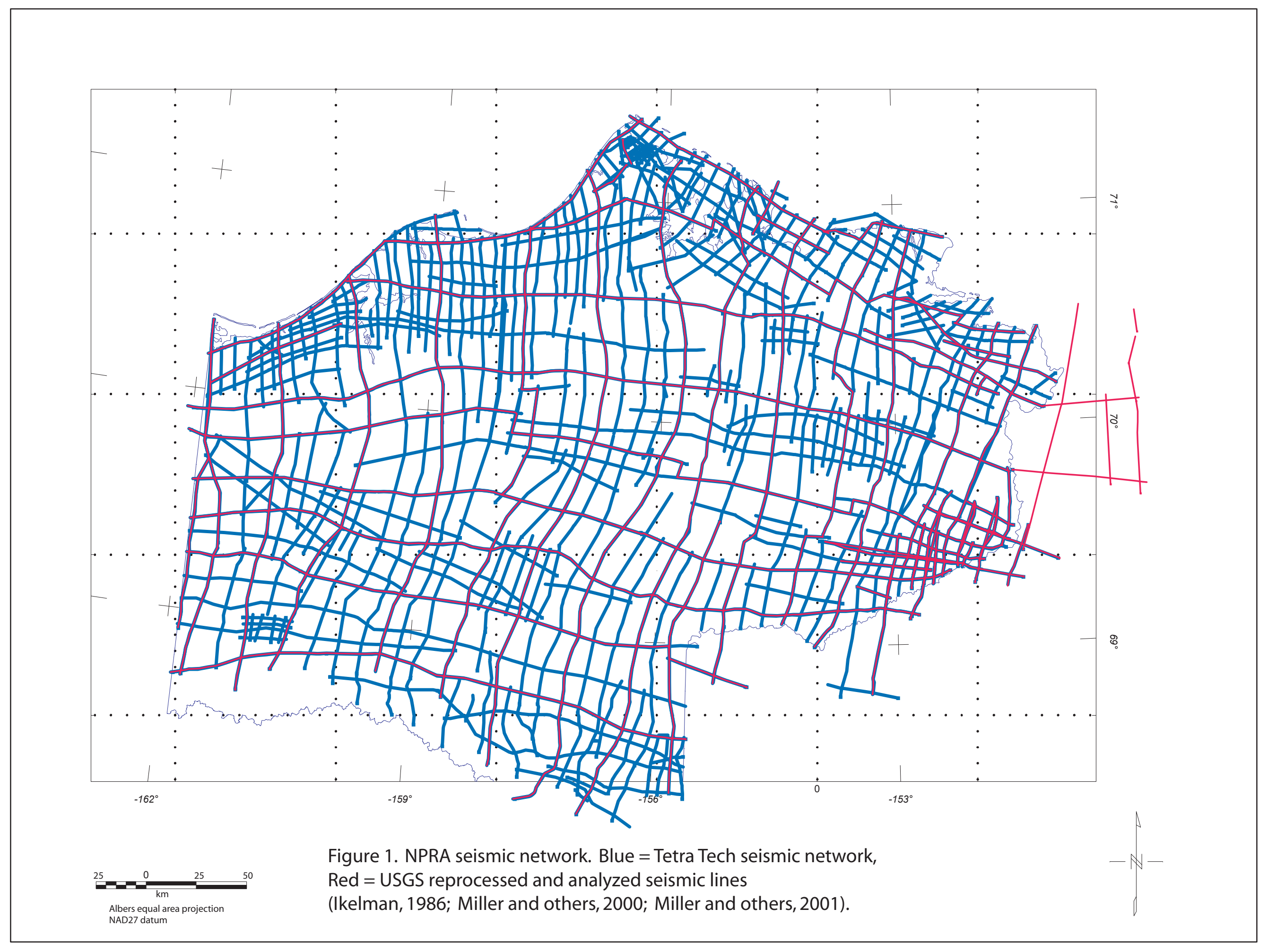




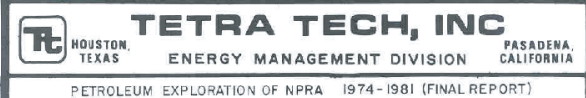

\section{GEOLOGIC COLUMN}

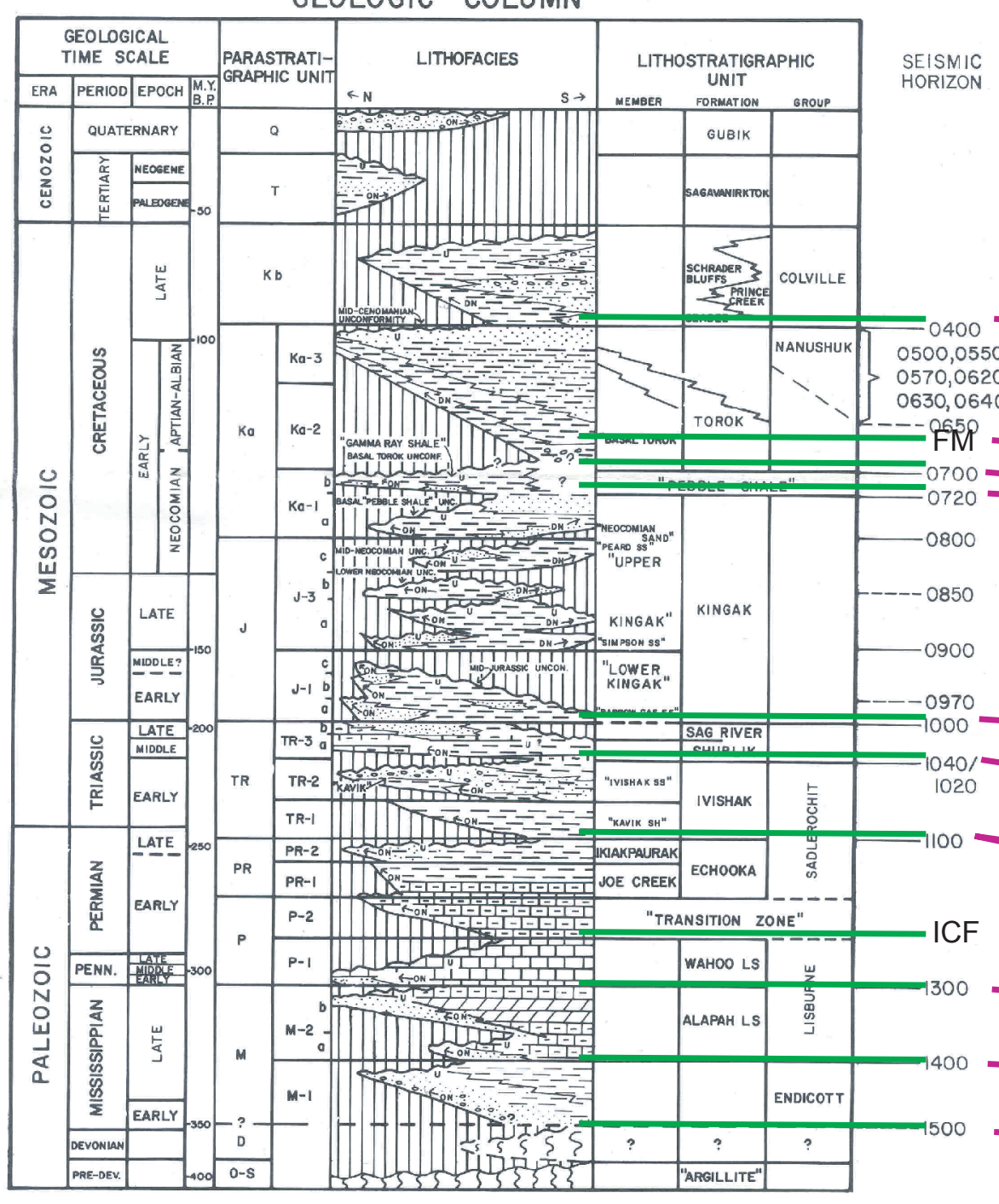

Figure 2 - Relationship of older Tetra Tech and recent USGS stratigraphic horizons
Horizon

Abbrev.

(this report)

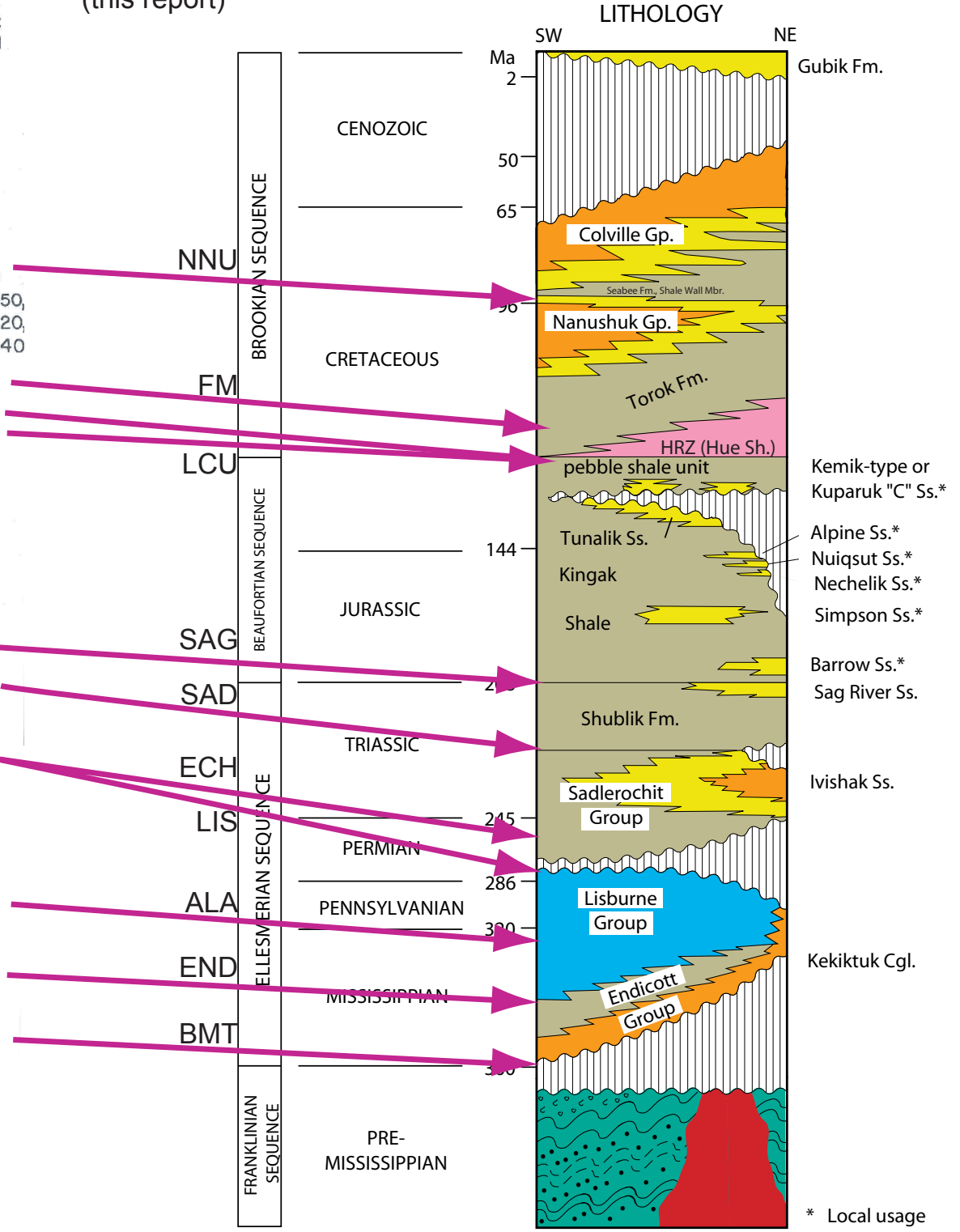


TABLE 1 - Tetra Tech maps digitized by the USGS

\begin{tabular}{|c|c|c|c|c|c|c|c|}
\hline \multirow{2}{*}{\multicolumn{2}{|c|}{$\begin{array}{l}\text { Map Name } \\
\text { DEPTHS }\end{array}$}} & \multirow[t]{2}{*}{ Unit Name } & \multicolumn{2}{|c|}{ Abbrev. Map No. } & \multirow[t]{2}{*}{ Reference } & \multirow{2}{*}{ Scale } & \multirow{2}{*}{ \# Points XYZ Filename } \\
\hline & & & & & & & \\
\hline 1 & Depth Map - Seismic Horizon 1500 & Basement & BMT & Map ?? & TT 8200 & $1: 500,000$ & 46478 Depths 1500 \\
\hline & TIMES & & & & & & \\
\hline 2 & Shallow Cret. Horizons 400, 450, 500, 550 & Nanushuk & NNU & Map 50 & TT 8200 & $1: 500,000$ & 60645 Times0500 \\
\hline 3 & FM Horizon (Time) & Fortress Mtn & FM & Plate III & TT 8003 & $1: 250,000$ & 43932 TimesFM \\
\hline 4 & Horizon 0700 Time "Top of Ka-1" & Pebble Shale & LCU & Map 39 & TT 8200 & $1: 500,000$ & 77420 Times 0700 \\
\hline 5 & Horizon 0720 Time "Pebble Shale" & Kingak & & Map 34 & TT 8200 & $1: 500,000$ & 46029 Times 0720 \\
\hline 6 & Horizon 1000 Time "Top of TR-3" & Sag River & SAG & Map 20 & TT 8200 & $1: 500,000$ & 35836 Times 1000 \\
\hline 7 & Horizon 1020 Time "Top of TR-2?" & Ivishak? & & Map 17 & TT 8200 & $1: 500,000$ & 64910 Times 1020 \\
\hline 8 & Horizon 1040 Time "Top of TR-2" & Ivishak & SAD & Map 14 & TT 8200 & $1: 500,000$ & 26111 Times 1040 \\
\hline 9 & Horizon 1100 Time "Top of PR" & Echooka & $\mathrm{ECH}$ & Map 9 & TT 8200 & $1: 500,000$ & 66768 Times 1100 \\
\hline 10 & Intermediate Composite Features (Time) & Mid Paleozoic & ICF & Plate XXV & TT 8003 & $1: 250,000$ & 8216 TimesICF \\
\hline 11 & Horizon 1300 Time "Top of M-2" & Alapah & ALA & Map 6 & TT 8200 & $1: 500,000$ & 21748 Times 1300 \\
\hline 12 & Horizon 1400 Time "Top of M-1" & Endicott & END & Map 3 & TT 8200 & $1: 500,000$ & 10652 Times 1400 \\
\hline 13 & Horizon 1500 Time "Acoustic Basement" & Basement & BMT & Map 1 & TT 8200 & $1: 500,000$ & 61418 Times 1500 \\
\hline & FAULTS & & & & & & \\
\hline 14 & Shallow Cret. Horizons 400, 450, 500, 550 & Nanushuk & NNU & Map 50 & TT 8200 & $1: 500,000$ & 1385 Faults0500 \\
\hline 15 & FM Horizon (Time) & Fortress Mtn & FM & Plate III & TT 8003 & $1: 250,000$ & 8884 FaultsFM \\
\hline 16 & Horizon 0700 Time "Top of Ka-1" & Pebble Shale & LCU & Map 39 & TT 8200 & $1: 500,000$ & 3643 Faults0700 \\
\hline 17 & Horizon 0720 Time "Pebble Shale" & Kingak & & Map 34 & TT 8200 & $1: 500,000$ & 664 Faults 0720 \\
\hline 18 & Horizon 1000 Time "Top of TR-3" & Sag River & SAG & Map 20 & TT 8200 & $1: 500,000$ & 151 Faults 1000 \\
\hline 19 & Horizon 1020 Time "Top of TR-2?" & Ivishak? & & Map 17 & TT 8200 & $1: 500,000$ & 2536 Faults 1020 \\
\hline 20 & Horizon 1040 Time "Top of TR-2" & Ivishak & SAD & Map 14 & TT 8200 & $1: 500,000$ & 37 Faults 1040 \\
\hline 21 & Horizon 1100 Time "Top of PR" & Echooka & $\mathrm{ECH}$ & Map 9 & TT 8200 & $1: 500,000$ & 1779 Faults 1100 \\
\hline 22 & Intermediate Composite Features (Time) & Mid Paleozoic & ICF & Plate XXV & TT 8003 & $1: 250,000$ & 1510 FaultsICF \\
\hline 23 & Horizon 1300 Time "Top of M-2" & Alapah & ALA & Map 6 & TT 8200 & $1: 500,000$ & 174 Faults 1300 \\
\hline 24 & Horizon 1400 Time "Top of M-1" & Endicott & END & Map 3 & TT 8200 & $1: 500,000$ & 475 Faults 1400 \\
\hline 25 & Horizon 1500 Time "Acoustic Basement" & Basement & BMT & Map 1 & TT 8200 & $1: 500,000$ & 3713 Faults 1500 \\
\hline & VELOCITIES & & & & & & \\
\hline 26 & Surface to Torok Clinothem & Ceno. Lt Cret. & & Map 53 & TT 8200 & $1: 500,000$ & 755 Velo0500 \\
\hline 27 & Surface to Horizon 0700 & Brookian & & Map 54 & TT 8200 & $1: 500,000$ & 1174 Velo0700 \\
\hline 28 & Between horizons 1000 and 0700 & Beaufortian & & Map 56 & TT 8200 & $1: 500,000$ & 10560 Velo1000 \\
\hline 29 & Between horizons 1100 and 1000 & Upper Elles. & & Map 57 & TT 8200 & $1: 500,000$ & 8754 Velo1100 \\
\hline 30 & Between horizons 1500 and 1100 & Lower Elles. & & Map 58 & TT 8200 & $1: 500,000$ & 9573 Velo1500 \\
\hline
\end{tabular}

References

TT 8003 - Tetra Tech Report No. 8003, 1981, Summary Report FY '80

TT 8200 - Tetra Tech Report No. 8200, 1982, Petroleum Exploration of NPRA, 1974-1981 Final Report 
TT minus USGS

Difference stats (kft)

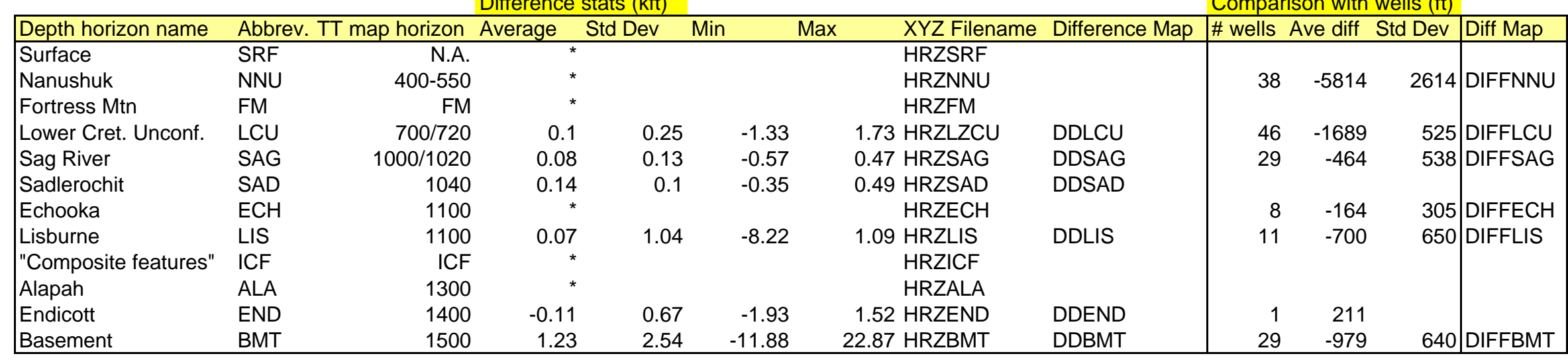

* = Not mapped by USGS 
Table 3 - Summary of closure statistics

\begin{tabular}{|c|c|c|c|c|c|c|c|c|c|c|c|c|c|c|}
\hline \multirow{3}{*}{\begin{tabular}{|l|} 
Horizon \\
Nanushuk \\
\end{tabular}} & \multirow[b]{2}{*}{ Play name } & \multirow{2}{*}{$\begin{array}{l}\text { Map area } \\
\text { (k acres) }\end{array}$} & \multirow[b]{2}{*}{$\mathrm{Cl}(\mathrm{ft})$} & \multirow[b]{2}{*}{ \# CLS } & \multicolumn{2}{|c|}{ Area (k acres) } & \multirow[b]{2}{*}{ M95 } & \multicolumn{2}{|c|}{ Height $(\mathrm{ft})$} & \multirow[b]{2}{*}{ M95 } & \multicolumn{2}{|c|}{ Top elevation (kft) } & \multirow[b]{2}{*}{ M95 $\quad$ Spreadsheet } & \multirow[b]{2}{*}{ Map } \\
\hline & & & & & M5 & M50 & & M5 & M50 & & M5 & M50 & & \\
\hline & Brookian Topset Structural & 13546 & 20 & 213 & 0.25 & 1.50 & 47.50 & 12 & 166 & 1439 & -7.83 & -3.55 & 4.75 CLSDTSNNU & CLSDTSNNU \\
\hline FM & Torok Structural & 9075 & 20 & 127 & 0.25 & 4.75 & 51.25 & 18 & 272 & 1396 & -14.24 & -8.45 & -1.20 CLSTORFM & CLSTORFM \\
\hline LCU & Torok Structural & 15143 & 250 & 70 & 0.25 & 1.00 & 46.50 & 11 & 128 & 761 & -24.89 & -17.66 & -12.10 CLSTORLCU & CLSTORLCU \\
\hline Sag River & Sag River* (obsolete play) & 8189 & 20 & 20 & 0.25 & 4.00 & 68.75 & 6 & 35 & 97 & -9.17 & -8.91 & -7.85 CLSSAGSAG & CLSSAGSAG \\
\hline Sadlerochit & Ellesmerian Ivishak & 8999 & 20 & 58 & 0.25 & 1.25 & 18.25 & 9 & 31 & 84 & -12.14 & -9.35 & -8.06 CLSSADSAD & CLSSADSAD \\
\hline \multirow[t]{3}{*}{ Echooka } & Ellesmerian Echooka $(\mathrm{N}+\mathrm{S})$ & 16825 & 20 & 16 & 3 & 6.10 & 30.00 & 40 & 86 & 200 & -28.00 & -25.50 & $-10.00 \mathrm{CLSECHECH}$ & CLSECHECH \\
\hline & Ellesmerian Echooka North & & 20 & 7 & 4 & 6.50 & 59.00 & 51 & 76 & 104 & -28.00 & -25.00 & -9.00 CLSECHECH & CLSECHECH \\
\hline & Ellesmerian Echooka South & & 20 & 9 & 2.75 & 5.50 & 17.25 & 34 & 95 & 216 & -28.00 & -25.00 & -14.00 CLSECHECH & CLSECHECH \\
\hline \multirow[t]{3}{*}{ Lisburne } & Ellesmerian Lisburne $(\mathrm{N}+\mathrm{S})$ & 10298 & 20 & 78 & 0.25 & 1.25 & 15.50 & 14 & 46 & 146 & -18.75 & -10.79 & -9.92 CLSLISLIS & CLSLISLIS \\
\hline & Ellesmerian Lisburne North & & 20 & 54 & 0.25 & 1.25 & 15.50 & 13 & 44 & 115 & -15.00 & -10.50 & $-9.00 \mathrm{CLSL}$ & CLSLISLIS \\
\hline & Ellesmerian Lisburne South & & 20 & 24 & 0.25 & 1.00 & 20.00 & 10 & 66 & 200 & -20.00 & -15.00 & -14.00 CLSLISLIS & CLSLISLIS \\
\hline ICF & Thrust Belt & 986 & 250 & 31 & 0.25 & 1.75 & 14.00 & 9 & 322 & 1004 & -13.95 & -10.06 & -4.89 CLSTHUICF & CLSTHUICF \\
\hline \multirow[t]{3}{*}{ Alapah } & Ellesmerian Lisburne(N+S) & 6688 & 20 & 43 & 0.25 & 1.25 & 21.00 & 8 & 43 & 174 & -27.89 & -12.26 & -10.31 CLSLISALA & CLSLISALA \\
\hline & North & & 20 & 34 & 0.25 & 1.40 & 63.00 & 5 & 45 & 150 & -27.00 & -11.50 & -10.00 CLSLISALA & CLSLISALA \\
\hline & South & & 20 & 9 & 0.25 & 1.75 & 21.00 & 7 & 37 & 186 & -21.00 & -15.00 & -11.00 CLSLISALA & CLSLISALA \\
\hline Endicott & Ellesmerian Endicott South & & 20 & 31 & 0.25 & 2.50 & 44.50 & 4 & 81 & 371 & -26.94 & -18.41 & -12.14 CLSENDEND & CLSENDEND \\
\hline Basement & Ellesmerian Endicott South & 7224 & 20 & 58 & 0.25 & 1.50 & 34.25 & 25 & 135 & 662 & -27.98 & -18.75 & -11.39 CLSENDBMT & CLSENDBMT \\
\hline
\end{tabular}

$\mathrm{Cl}=$ contour interval

\# CLS = number of closures found

Ratio $=$ Height $($ feet $) /$ Area (kiloacres)

$\mathrm{R}^{\wedge} 2$ = Goodness of fit

Spreadsheet $=$ file name of spreadsheet in accompanying spreadsheet directory

Map = file name of map in accompanying map directory 
Table 4 - Closure area vs height statistics

\begin{tabular}{|c|c|c|c|c|c|c|c|c|c|c|c|c|c|c|c|c|c|c|c|}
\hline \multirow[b]{3}{*}{ Play } & \multirow[b]{3}{*}{ Horizon } & \multirow[b]{3}{*}{$\# \mathrm{CL}$} & \multicolumn{6}{|c|}{ Data statistics } & \multicolumn{10}{|c|}{ Correlation statistics } & \multirow{3}{*}{$\begin{array}{l}\text { Detailed } \\
\text { Stats }\end{array}$} \\
\hline & & & \multicolumn{3}{|c|}{ Area (k acres) } & \multicolumn{3}{|c|}{ Height (feet) } & \multicolumn{2}{|c|}{ Height $=X+Y^{*}$ Area } & \multirow{2}{*}{$\begin{array}{l}\text { Correl } \\
\mathrm{R}^{\wedge} 2 \\
\end{array}$} & \multirow{2}{*}{$\begin{array}{l}\text { Signif. } \\
\mathrm{t}\end{array}$} & \multicolumn{2}{|c|}{ Pearson } & \multicolumn{2}{|c|}{ Spearman } & \multicolumn{2}{|c|}{ Log Correl } & \\
\hline & & & Mean & Median & $\mathrm{D}$ & Mean & Median & D & $\mathrm{Y}$ & & & & $r$ & $\mathrm{t}$ & $r$ & $\mathrm{t}$ & $\mathrm{R}^{\wedge} 2$ & Pearson & \\
\hline Brookian Topset Structural & NNU & 213 & 10.8 & 1.5 & 0.28 & 395 & 166 & 0.22 & 235.0 & 14.9 & 0.30 & 9.4 & 0.54 & 9.4 & 0.57 & 10.1 & 0.34 & 0.58 & NNUSTATS \\
\hline Torok Structural & FM & 127 & 12.3 & 4.8 & 0.24 & 408 & 272 & 0.17 & 182.0 & 18.3 & 0.54 & 12.0 & 0.73 & 12.0 & 0.76 & 13.0 & 0.50 & 0.71 & FMSTATS \\
\hline Torok Structural & LCU & 70 & 8.0 & 1.0 & 0.32 & 306 & 138 & 0.30 & 121.0 & 23.1 & 0.45 & 7.4 & 0.67 & 7.4 & 0.58 & 5.9 & 0.38 & 0.62 & LCUSTATS \\
\hline Sag River* (obsolete play) & SAG & 20 & 16.1 & 4.1 & 0.34 & 53 & 36 & 0.22 & 24.6 & 1.8 & 0.76 & 7.5 & 0.87 & 7.5 & 0.85 & & 0.74 & 0.86 & SAGSTATS \\
\hline Ellesmerian Ivishak & SAD & 58 & 3.8 & 1.3 & 0.28 & 42 & 31 & 0.18 & 24.7 & 4.5 & 0.51 & 7.6 & 0.71 & 7.6 & 0.63 & 6.0 & 0.46 & 0.68 & SADSTATS \\
\hline Ellesmerian Echooka $(\mathrm{N}+\mathrm{S})$ & $\mathrm{ECH}$ & 16 & 11.4 & 6.1 & 0.28 & 94 & 86 & 0.23 & 84.5 & 0.8 & 0.05 & 0.9 & 0.23 & 0.9 & 0.57 & & & & ECHSTATS \\
\hline North & $\mathrm{ECH}$ & 7 & 13.6 & 6.5 & 0.46 & 73 & 76 & 0.24 & 69.7 & 0.2 & 0.04 & 0.5 & 0.21 & 0.5 & 0.57 & & & & ECHSTATS \\
\hline South & $\mathrm{ECH}$ & 9 & 9.6 & 5.5 & 0.31 & 110 & 95 & 0.23 & 33.6 & 7.9 & 0.65 & 3.6 & 0.80 & 3.6 & 0.62 & & & & ECHSTATS \\
\hline Ellesmerian Lisburne & LIS & 78 & 3.4 & 1.3 & 0.31 & 61 & 47 & 0.17 & 36.2 & 8.1 & 0.66 & 12.2 & 0.67 & 7.4 & 0.58 & 5.9 & 0.36 & 0.60 & LISSTATS \\
\hline North & LIS & 54 & 3.0 & 1.3 & 0.32 & 53 & 44 & 0.17 & 39.0 & 4.7 & 0.39 & 5.7 & 0.62 & 5.7 & 0.56 & 4.9 & 0.35 & 0.59 & LISSTATS \\
\hline South & LIS & 24 & 4.5 & 1.0 & 0.33 & 79 & 66 & 0.18 & 48.3 & 6.8 & 0.61 & 5.9 & 0.78 & 5.9 & 0.58 & 3.3 & 0.38 & 0.62 & LISSTATS \\
\hline Ellesmerian Lisburne & ALA & 43 & 6.0 & 1.3 & 0.39 & 61 & 43 & 0.23 & 36.8 & 6.6 & 0.48 & 6.9 & 0.69 & 6.9 & 0.72 & 7.4 & 0.56 & 0.75 & ALASTATS \\
\hline North & ALA & 34 & 7.5 & 1.4 & 0.43 & 56 & 45 & 0.20 & 44.7 & 1.5 & 0.45 & 5.2 & 0.67 & 5.2 & 0.68 & 5.3 & 0.48 & 0.69 & ALASTATS \\
\hline South & ALA & 9 & 6.0 & 1.8 & 0.37 & 77 & 37 & 0.27 & 23.9 & 8.9 & 0.88 & 7.2 & 0.94 & 7.2 & 0.92 & & 0.94 & 0.97 & ALASTATS \\
\hline Thrust Belt & ICF & 31 & 6.0 & 1.8 & 0.31 & 449 & 322 & 0.19 & 208.1 & 48.6 & 0.39 & 4.3 & 0.72 & 5.6 & 0.72 & 5.6 & 0.46 & 0.68 & ICFSTATS \\
\hline Ellesmerian Endicott South & END & 31 & 12.2 & 2.5 & 0.34 & 126 & 81 & 0.23 & 65.0 & 5.0 & 0.58 & 6.4 & 0.76 & 6.4 & 0.86 & 9.1 & 0.76 & 0.87 & ENDSTATS \\
\hline Ellesmerian Endicott South & BMT & 58 & 7.9 & 1.6 & 0.27 & 200 & 135 & 0.22 & 73.2 & 16.1 & 0.72 & 12.2 & 0.85 & 12.2 & 0.70 & 8.1 & 0.57 & 0.75 & BMTSTATS \\
\hline
\end{tabular}

$\# \mathrm{CL}=$ number of closures

$\mathrm{D}=$ normality test statistic (all tests show evidence of non-normality)

$R^{\wedge} 2$ = standard least square measure of linear fit

Pearson $r=$ Pearson's correlation coefficient for normal populations

Pearson $\mathrm{t}=\mathrm{t}$-test statistic (all tests implied that slope does not $=0$ )

Spearman $r=$ Spearman's rank correlation coefficient for non-normal distributions

Spearman $\mathrm{t}=\mathrm{t}$-test statistic (all tests implied that slope does not $=0$ )

Log Correl $=$ Correlation statistics based on natural log of area vs. natural log of height

Detailed Stats = File names for complete reports on statistics (tables and graphs - all *.pdf files)

(Files in Stats directory accompanying this report) 